\title{
Comunicación, poder y democracia líquida en la Casa Blanca: el relato televisivo de Scandal y House of Cards
}

\section{Communication, power and liquid democracies in the White House: TV story of Scandal and House of Cards.}

\author{
Virginia Guarinos y Valeriano Durán Manso \\ Universidad de Sevilla y Universidad de Cádiz \\ http://dx.doi.org/10.12795/AdMIRA.2017.01.06
}

\section{RESUMEN}

Aunque existe el concepto de "democracia líquida" como opción de democracia participativa, en este texto se utilizará con la acepción de pensamiento líquido (Damian Hughes). En un contexto de sociedades de lo efímero, se analiza este fenómeno en dos series de ficción norteamericanas, Scandal y House of Cards, donde los medios de comunicación y la comunicación institucional son fundamentales en la construcción de una democracia no tan real como aparenta. La lucha y el mantenimiento del poder a través del gobierno de EEUU ha sido tratado en múltiples dramas políticos televisivos, como El ala oeste de la Casa Blanca -de las pioneras de la hipertelevisión-, Homeland, Veep o, la última, The Residents. No obstante, en las cinco temporadas emitidas de Scandal (ABC, 2012-) y las tres de House of Cards (Netflix, 2013-) juega un papel vital la comunicación interna, externa e institucional, como arma de cohesión democrática, y de destrucción o desorientación desde el poder. La metodología utilizada será la de Narrativa AV, a partir de los niveles de focalización metafórico, epistémico y literal. En este sentido, se analizarán las acciones, acontecimientos y transformaciones, así como los personajes en sus tres dimensiones: como persona, como rol y como actantes.

\section{PALABRAS CLAVE}

Relato, televisión, comunicación, poder, democracia, Casa Blanca

\begin{abstract}
Although there is the concept of "liquid democracy" as an option of participatory democracy, in this text will be used with the meaning of liquid thought (Damian Hughes). In a context of societies of the ephemeral, examines this phenomenon in two American fiction series, Scandal and House of Cards, where the media and institutional
\end{abstract}


communication are essential in the construction of a democracy not as real as it seems. The fight and the maintenance of power through the US Government has been treated in multiple political television dramas, such as The West Wing -pioneer of the hipertelevision-, Homeland, Veep, or the last, The Residents. However, in five seasons issued of Scandal (2012-), and the three of House of Cards (Netflix, 2013-) plays a vital role in the internal, external and institutional communication, as a democratic cohesion weapon and destruction or disorientation from the power. The methodology used will be of audiovisual narrative, from the metaphorical, epistemic and literal focus levels. In this sense, we will analyse the actions, events and transformations, as well as the characters in its three dimensions: as a person, as a role and as actants.

\section{KEYWORDS}

Story, television, communication, power, democracy, White House 


\section{Introducción. Sociedad y democracia líquidas, política y televisión}

Muchas son las perspectivas de lo líquido en la actualidad, aplicadas a sociedad, comportamiento, política, psicología... Algunas son positivas y otras no tanto. Edward de Bono afirma que la mayoría de nuestros errores proceden de nuestro pensamiento sólido, aquel que se resiste a los cambios, mientras que el pensamiento líquido, deriva, según Hughes (2011), en la creatividad que acepta y promueve los cambios para conseguir el éxito, equivalente al pensamiento lateral de De Bono (2006). La capacidad para adaptarse a cualquier circunstancia y variación de perspectiva ante los hechos adversos, como una forma de pensamiento creativo, implica cambio constante. Este principio, que en el arte puede resultar enriquecedor, se aplica de forma extendida también al universo empresarial, y con él, a la economía. De la economía a la política solo hay un paso. Hughes define tres tipos de personas: los que preguntan qué ha sucedido, los que ven con claridad lo que sucede y los que provocan que las cosas sucedan. El último es el liquidthinker, el pensador líquido, el hombre de éxito. El pensador líquido es capaz de "licuar" conceptos, deshacerlos, y son capaces de salir de un contexto para dar coherencia y resolver retos, eliminando limitaciones y conflictos y haciendo propuestas que generen soluciones inmediatas. Solo estas premisas ya recuerdan mucho las tareas que desarrolla un spin-doctor. No obstante, las recomendaciones para practicar pensamiento líquido son: reinventarse, divertirse con ello, adaptarse a las circunstancias, mantenerse siempre en movimiento, conservar la cabeza fría, pero... también ser libres y ser transparentes, dos ac(-p-)titudes que se distancian de este comportamiento cuando lo ejerce un spin-doctor.

El sociólogo polaco Zygmunt Bauman acuña la terminología "modernidad líquida" para nuestra época, la que mantiene una sociedad líquida, opuesta a la estática anterior, en la que la rigidez es cambiada, gracias a la globalización y como consecuencia de ella, por una vida de comienzos continuos y breves e indoloros finales, sin lazos firmes, sin compromisos, con estructuras fundadas en la razón pero siempre inestables, frágiles, sin consolidación y de constante incertidumbre. Esto que afecta a los individuos, globalizados e imperializados, también afecta a sus gobiernos, al borde de la ruptura en todo momento, tal como aparecen reflejados en las series, cambiantes y recuperando el 
control a través de la manipulación y el uso de los medios como vehículo permanente de engaño a la población, que ignora esos movimientos la mayor parte de las veces.

A ello es a lo que nos referimos cuando en el título de este trabajo incluimos el tándem "democracia líquida" y no al sentido primario de esos términos, entendida como democracia participativa, democracia directa con delegación de voto y parlamento virtual $^{1}$.

La televisión como medio, pero también como vehículo social, no escapa a ninguna de estas tendencias de época, pero tampoco renuncia a denunciarlo. La crisis contemporánea en todos los órdenes y especialmente el económico ha producido que las televisiones observen, fuera de los espacios canónicos para ello, como son los informativos, los hechos desde el infoentretenimiento y desde la ficción. La política, elemento causante para muchos de la crisis que padece occidente, es tratada a diario, con tono más o menos humorístico y siempre incisivo en el infotaitment y, a pesar de todo ello en época de crisis, de apariciones reiteradas de corrupción política y financiera, desde El ala oeste de la Casa Blanca, como afirma Tous, y muchos de los dramas políticos televisivos se ha contribuido a tareas de divulgación política más que otros medios destinados a ello, como otros programas de no ficción (2015: 16), al menos de esa otra política no oficial, no visible.

Existen estudios de un lado y de otro: la imagen de los políticos reales convertidos en personajes (Chuck, 2011) a través de redes sociales de ciudadanos, y los personajes que hacen de políticos en la ficción, y que en algunos momentos, de forma premonitoria, representan acciones que luego suceden en la política real, en tanto que varias publicaciones divulgativas atestiguan que los propios políticos ven esas series, les sirven, como a todo espectador tanto de estereotipo como de prototipo y modelo de comportamiento. Rodríguez Vidales afirma que "series como El ala oeste de la Casa Blanca (1999-2006), Borgen (2010-2013) y House of Cards (2012-...) abordan detalladamente la política y el poder. Sus tramas son capaces de adelantar acontecimientos e incluso inspirar a la propia realidad política. Provocan, incluso, que los grandes líderes políticos hablen de ellas" (2015: 776).

\footnotetext{
${ }^{1}$ Véase http://www.democracialiquida.org/ y http://democracialiquida.es/ (14/02/2016).
} 
En cualquier caso, este hecho de aparición de la política en la ficción cinematográfica y televisiva trasciende más allá de cuando sucede de forma explícita. El trabajo de Eilders y Nitsch (2015), sobre 114 películas y 48 series norteamericanas indica que, a pesar de pertenecer en su mayoría a producciones de géneros exitosos como el thriller o la fantasía, en universos no realistas, existe una alta carga de política y relaciones políticas entre personajes y en el diseño de los conflictos de las tramas.

\section{Objetivos}

Este trabajo tiene como objetivo principal reflexionar sobre cómo aparece representada la estrecha relación entre el poder político y la comunicación institucional, interna y externa en los relatos televisivos de dos de las series de ficción norteamericanas de más impacto en los últimos años: Scandal (ABC, 2012-) y House of Cards (Netflix, 2013-). No obstante, de este propósito principal parten los siguientes objetivos específicos:

- Abordar las relaciones entre la política y la comunicación presentes en la ficción televisiva norteamericana actual, donde las numerosas series centradas en los círculos de poder de alto nivel -especialmente en la Casa Blanca-, y estrenadas en los últimos años, constituyen casi un subgénero en la pequeña pantalla.

- Realizar un análisis de dos de las series de televisión más representativas de esta temática -y de mayor éxito-, como son Scandal y House of Cards, cuyas tramas, acciones, temas y personajes cuestionan las fórmulas democráticas tradicionales, y ponen de relieve la presencia del denominado pensamiento líquido.

- Tratar la relevancia de ambas series y su influencia en el ámbito televisivo, tanto norteamericano como europeo, debido al cuestionamiento de las relaciones entre el poder político y el poder de los medios de comunicación, en el marco de una nueva edad dorada de la ficción televisiva de Estados Unidos.

\section{Análisis}

\subsection{Política, comunicación y ficción televisiva}

La próxima serie que se espera, The Resident (Fox 21), en fase de preproducción, creada por Kevin Spacey, a medio camino entre House of Cards (Netflix, 2013-) y Downton Abbey (NBC, 2010-), es otro drama localizado en la Casa Blanca, como tantos otros anteriores. Veep (HBO, 2012-), Madam Secretary (CBS, 2014-), The Brink (HBO, 
2015), Political Animals (USA Network, 2012), Homeland (Showtime, 2011-), Commander in Chief (ABC, 2005-2006) componen una larga lista de títulos que desarrollan en sus tramas la vida política de alto nivel en los gobiernos de naciones, casi siempre de EEUU, aunque también en políticas no presidenciales, sino locales, como el caso de Boss (Grammet Productions y Lionsgate TV, 2011-2012), centrada en la alcaldía de Chicago. De la política danesa, como en Borgen (Danmark Radio, 20102013), a la británica, como la primera House of Cards (miniserie de la BBC, 1990) o Secret State (Channel 4, 2012), no solo se cultiva en clave trágica, también en clave de comedia, aunque en mucha menor medida, como en Veep (HBO, 2012), sobre la vicepresidenta de los EEUU, o en Yes, Minister (BBC, 1980-1982) y Yes, Prime Minister (BBC, 1986-1987) sobre la presidencia británica² ${ }^{2}$

Entre tan diversos tipos de series políticas, existe un elemento común en todas ellas, el uso de los medios de comunicación y su relación con el poder político para producir o resolver tramas principales. No es de extrañar, como afirma Ros, que en la televisión de EEUU "la representación del imaginario político ha sido parte consustancial de los valores fundacionales democráticos" con una visión crítica donde "la ficción asumiría así una función no tan distante a la que en teoría debe ejercer el periodismo" (2015: 158). Dentro de los dramas políticos en relación a la comunicación existen las series que se centran en medios de comunicación que trabajan cubriendo información política o que reflejan, a través de sus directivos, el peso de la política en las decisiones editoriales o coberturas de la información (como es el caso de The Newsroom (HBO, 2012-2014), y las que directamente se localizan en los centros de gobierno (como en El ala oeste de la Casa Blanca); la series dramáticas políticas y su relación con la comunicación contemplan los hechos político-comunicativos o bien desde la focalización del poder o bien desde la focalización de la información. Y en todas las recientes publicaciones académicas sobre series y política, raro es el caso que no mencione dicha relación e importancia, que, sabemos, no es solo ficcional, sino reflejo de la realidad empírica social actual.

\footnotetext{
${ }^{2}$ Mención aparte merece el caso español, donde solo una serie ha destacado por su contenido relacionado con la política y la corrupción, Crematorio (Canal +, 2011), además de la inocente sitcom Moncloa, ¿dígame? (Telecinco, 2001).
} 
Dichas relaciones, desde la focalización de poder, ya no desde la perspectiva del periodismo, ha tenido uno sus ejemplos más explícitos, aunando la importancia de la comunicación y de las nuevas tecnologías en las campañas, en The Wood Wife (CBS, 2009-2015) en la que se pone de manifiesto y se denuncia el fraude electoral, llegando, como es en la realidad, a mostrar la importancia no ya de los medios tradicionales sino de internet y las redes sociales, más allá de la rueda de prensa y la asesoría de imagen. Pero no todo es tan simple, ni se reduce únicamente a destapar (o tapar) fraudes electorales.

Las dos series que aquí se analizan, de cortes muy diferentes, ofrecen dos visiones de uso y relación del poder político con la comunicación interesantes de cotejar, precisamente por la factura tan distante, desde el punto de vista del relato y el universo de la historia que plantean: House of Cards, desde el descreimiento y el cinismo del antihéroe psicópata que es su personaje principal, y Scandal, desde la construcción más cercana al culebrón norteamericano, a la telenovela, con tintes de melodrama romántico, y, aun así, próximas en el trasfondo sobre política y comunicación .

\subsection{Estudios de caso}

\subsubsection{House of Cards}

Estrategia, manipulación, inteligencia, ambición, traición, poder, y comunicación. Estas palabras marcan, articulan y determinan las decisiones y las actuaciones del congresista norteamericano Francis J. Underwood, interpretado por Kevin Spacey, en la serie de televisión House of Cards, quien es capaz de todo con tal de conseguir sus propósitos. Perteneciente al partido demócrata, el protagonista se sitúa en el entorno más directo del presidente de Estados Unidos y esta posición le permite manejar los hilos políticos de la Casa Blanca a través de la comunicación y el poder. Frank aprendió los valores del honor, el deber y el respeto -tal y como recuerda en la primera temporada-, en la principal academia militar de Carolina del Sur, pero, en realidad, sólo se quedó en la teoría. Graduado en Derecho por Harvard y líder de la Cámara de los Representantes del Partido Demócrata, un total de 22 años avalan su carrera política. El punto de partida de la serie es la traición y este concepto tiene como respuesta la venganza y la codicia a toda costa, incluyendo presiones, abusos, o incluso la muerte. 
Frank había acordado con el candidato a la presidencia de Estados Unidos Garret Walker que si ganaba las elecciones sería nombrado Secretario de Estado, pero cuando éste se convierte en presidente le comunica que su nombramiento no se podrá realizar. A raíz de este incidente, se siente traicionado porque ayudó a Walker en su camino hacia la Casa Blanca, así que diseña un plan contra él en el que sus contactos políticos y del ámbito periodístico tienen un papel crucial. Para ello, inicia una estrecha relación con la joven reportera del diario The Washington Herald Zoe Barnes -encarnada por Kate Mara-, quien ansía crecer profesionalmente en el medio para el que trabaja. Su sed de poder se materializa al convertirse en vicepresidente en la segunda temporada y, sobre todo en la tercera, cuando Walker deja el cargo y es nombrado presidente, pero en el primer caso tiene que asesinar al congresista Peter Russo tras manipularlo a su antojo y en el segundo enfrentarse a su propio partido por su escasa popularidad. Sin duda, la serie "detalla lo sencillo que es manipular a los políticos si alguien conoce sus puntos débiles y como éstos reciben su premio o su castigo si no responden a las expectativas que de ellos esperan otros políticos o los votantes" (Rodríguez Vidales, 2015: 779).

El protagonista tiene una gran capacidad de resolución, es ágil, rápido y astuto, y como siente que puede conseguir cada vez más poder, esto le genera una ambición insaciable. Por ello, utiliza todos los medios para lograr el cargo de Secretario de Estado, pero cuando lo logra necesita seguir alimentando su ego en un mundo de depredadores. En sus distintas actuaciones, se puede ver que es frio, manipulador, y vengativo, a la vez que muy educado a nivel social y sensible en su esfera privada. Se trata de un claro ejemplo de pensador líquido porque medita, resuelve, gestiona, y decide con una gran rapidez, versatilidad y capacidad de adaptación. Además, suele conseguir que las cosas cambien según sus intereses sin que ello le suponga un gran esfuerzo y, lo que es más importante, sin que los demás lo noten. Con la excusa de trabajar por el bien común, el único interés que lo mueve es el personal, y en su afán no duda en tener a diversos periodistas como cómplices, interesados a su vez por su propio éxito. En este sentido, "Washington se presenta como la corrupta Roma, llena de políticos arribistas, arrastrados por el sexo, la codicia, la corrupción y el deseo de poder, que no dudan en apuñalarse los unos a los otros con una sonrisa" (García, 2014). 
A nivel personal, su amor platónico es un compañero de la academia militar pero oculta su sexualidad tras la fachada de un matrimonio ideal, aunque quiere a su esposa. Claire Underwood, interpretada por Robin Wright, es la mujer perfecta y desempeña el ideal de la Primera Dama norteamericana por su belleza, saber estar, elegancia y estilo. No obstante, estas cualidades esconden a una mujer inteligente y aguda cuyas formas de actuar son mucho más sibilinas y eficaces que las de su marido. Aunque es directora de la organización medioambiental sin ánimo de lucro Clean Water Initiative, su ambición la lleva a convertirse en embajadora de Naciones Unidas, objetivo que consigue en la tercera temporada cuando Frank ya es presidente. La pareja, que no tiene hijos por expresa decisión de él, apenas tiene relaciones sexuales, y esto hace que lleven vidas íntimas por separado. Además, son muy herméticos en lo que respecta a su vida privada, cuidan mucho su imagen pública, y forman un gran equipo, de manera que representan a la pareja perfecta ante la sociedad. Como es habitual en este tipo de series, mantener las apariencias y vender una imagen idílica es lo principal en la vida política de cara a los norteamericanos pues lo único que importa es alcanzar el poder y mantenerse en él. Los temas tienen un peso decisivo y, por este motivo, los seres de ficción contienen una gran complejidad psicológica y son atractivos, tanto los políticos como los periodistas:

\footnotetext{
En la serie, casi todos los personajes son complejos, con miserias y grandezas y con una gran ambición, capaces de vender su alma para incrementar su poder y su influencia política -con Underwood a la cabeza-, teniendo mucho cuidado con la opinión pública, que podría hacerles caer como un castillo de naipes (Rodríguez Vidales, 2015: 789).
}

Las tres temporadas completas, desde su estreno el 1 de febrero de 2013 -actualmente, se encuentra en emisión la cuarta temporada y está confirmada la quinta para 2017contienen un total de 39 capítulos $^{3}$. Cada una cuenta con una trama principal que gira en torno al propósito político de Frank y contiene una serie de subtramas ligadas a la consecución del mismo. Una de las particularidades de la serie es que el protagonista suele mirar a la cámara para dirigirse a los espectadores, y esta violación de la cuarta pared le otorga un papel especial con respecto a la historia. Asimismo, este detalle hace que el personaje se gane la confianza del público al hacerlo cómplice y que caiga bien a

\footnotetext{
${ }^{3}$ Se desconocen los datos de audiencia de la serie porque la cadena Netflix no los publica. No obstante, aunque no se trata de las más seguidas en Estados Unidos, es una de las favoritas del ex presidente Brack Obama, así como de otros políticos españoles, como se recogen en las diversas fuentes consultadas.
} 
pesar de sus malas artes. Si bien interpreta a un político ejemplar en lo que a imagen, relaciones sociales, e inteligencia respecta, las acciones de Frank -y conforme avanzan los capítulos también las de Claire-, carecen de escrúpulos y ponen de relieve que en la sociedad actual, y sobre todo en las altas esferas, está justificado casi todo con tal de llegar a lo más alto, pues, además, los ciudadanos ni se enteran ni tampoco cuentan. En este cometido, los medios de comunicación tienen un papel fundamental porque se convierten en los aliados perfectos de los políticos, y en su afán por tener exclusivas y ganarse su confianza, olvidan los valores deontológicos en los que se constituyen. Así, se pone de manifiesto que a la prensa no le interesa contar la verdad a los ciudadanos, sino acercarse al poder para mantener su estatus, y que los políticos necesitan tener medios afines para limpiar, manipular, cuidar, y difundir su imagen. Sin duda, "House of Cards basa toda su estrategia política en una ambición ilimitada, donde el idealismo es una simple fachada y la traición y la deslealtad las armas con las que validar su actuación" (Rodríguez Vidales, 2015: 780).

\subsubsection{Scandal}

Excesiva, tipo telenovela, Scandal reúne más características de culebrón norteamericano hibridado con serie de acción que de serie política. No obstante, la historia que desvela en sus cuatro temporadas completas denota la importancia de los medios de comunicación para el gobierno de EEUU, más allá del uso propagandístico o de manipulación que pueda hacerse desde ellos o a través de ellos en la campaña electoral, principal momento de cualquier político aspirante al gobierno en su relación con la alianza mediática. Más allá de lo visible, en esta serie se hace fundamental la existencia del uso de los medios por parte de los grupos ocultos de apoyo al candidato, algo ya visto en The Good Wife y llevado al extremo en esta otra serie, donde "el candidato es solo una cara visible de los complicados entresijos políticos, que en los últimos tiempos digitales además también incorporan a las personas anónimas de una manera activa" (Crisóstomo, 2015: 51).

El propio título de la serie ya sitúa al espectador en las coordenadas en las que las tramas se desenvuelven, las del escándalo de personajes influyentes, tapado o creado 
por la propia Casa Blanca utilizando a los medios de comunicación (televisión, prensa y redes sociales) a veces de forma oficial y la mayoría extraoficialmente.

Como muchos seguidores y bloggers la han calificado, es un culebrón pasado de rosca con el presidente de EEUU como protagonista, pero adictiva por la cantidad de tramas en cascada que ofrece por capítulo, con una estructura narrativa a medias entre la serialidad y la capitularidad. El universo de la historia transcurre a partir de una compañía de gestión de crisis dirigida por la ex responsable de comunicación de la Casa Blanca, y amante del presidente de los EEUU, que es, además de mujer, negra: Olivia Pope. El origen está basado en las experiencias de Judy Smith, ayudante de prensa de la Casa Blanca en el gobierno de George Bush, quien montó su propia empresa de gestión de crisis, llevando casos como el de Mónica Lewinsky o Wesley Snipes. Su tarea, ayudada por cuatro abogados y un ex marine y trabajador sucio de CIA, es ayudar a clientes poderosos en crisis personales o profesionales, políticas la mayoría. Su misión es controlar a la prensa y minimizar daños para el cliente en la resolución de la crisis; y sus métodos variados y sin ética: asesinato, robo, chantaje, secuestro, generación de rumores, noticias falsas. Desde infidelidades hasta violaciones, el trabajo del equipo de Olivia Pope es desviar la atención y salvar la reputación, normalmente generando nuevas noticas o mintiendo: la fórmula de relación es la de la rueda de prensa o filtración a medios a través de colaboradores externos a la propia empresa. En todo ello, el Presidente no suele enterarse o se entera muy posteriormente, sobre todo de lo que más directamente le afecta, llegando a tomar decisiones políticas que realmente no son suyas, aunque el entorno le lleva a creer que es así. Su propia elección como presidente procede de una campaña amañada por el equipo de colaboradores, que, a sus espaldas, negociaba por su cuenta, sin que él llegara a enterarse hasta bastante tiempo después. Además de Olivia, el otro personaje que controla el destino y la política de forma real, por sus manipulaciones, es su spin-doctor, Cyrus Beene, jefe de gabinete de la Casa Blanca, asesor y encargado de tapar todo lo que pueda afectar al presidente, sabiéndolo él o no. La figura del spin-doctor, aparecida ya en las series británicas, es la del encargado de "determinar las grandes líneas de actuación de los políticos a los que asesoran, y sobre todo de difundirlas en los medios de comunicación con el enfoque más adecuado a sus intereses" (López García, 2015: 175). 
Las cuatro temporadas completas desde abril de 2012 a septiembre de 2014, contienen 69 capítulos. Cada uno de los episodios supone una crisis para algún personaje, que de un modo u otro puede afectar al gobierno de los EEUU, algunos conflictos se alargan a más de un episodio y cada temporada tiene una trama principal, más personal que afecta profesionalmente a Olivia Pope y amorosamente a su relación tormentosa e ilícita con el casado Presidente. La resolución de cada conflicto termina con un acto de comunicación pública: o se da información falsa a la prensa, o se silencia la información o se genera una nueva información que tape o desvíe. Las ruedas y las notas de prensa son una constante de cada episodio, como también los programas de televisión a los que acuden los personajes o las grabaciones para los informativos en la Casa Blanca o lugares que visite la pareja presidencial. El rol que juega la prensa es el de una prensa adormecida, conformista y fácil de engañar. Y muchas de esas crisis se generan por la circulación pública de información inadecuada para los afectados, como rumor o como noticia en medios. Los medios son origen y/o final de los conflictos, siendo lo más importante la consecución de una apariencia pública ejemplar para la ciudadanía. Ni siquiera la prensa aparece como guardián del poder o vehículo al servicio del poder, como propaganda encubierta.

La serie cuenta con nueve millones de espectadores y ha sido exportada a 33 países. La showrunner de Scandal es Shonda Rhimes (también de Anatomía de Gray), lo cual es realmente sorprendente porque son muy pocas aún las mujeres que ocupan este rango en una producción audiovisual de ficción (Everet, 2015). Que Shonda Rhimes sea una mujer, como también Judy Smith, en cuya vida se inspira la serie, hace que deje de sorprender que una mujer negra ocupe esa titularidad y poder como personaje principal de una serie política, en la que tampoco es habitual que las presidentas sean mujeres: Geena Davis lo es en Commander in Chief, o la mujer primera ministra de Borgen, entre los escasos títulos existentes. Como testimonia Padilla, Judy Smith desarrolló su tarea en varios momentos históricos, importantes desde la comunicación e información, como la Guerra del Golfo o las relaciones con Irán y Kuwait. Tras dejar la Casa Blanca, creó la agencia de resolución de crisis Smith \& Company, base para crear la empresa Olivia Pope and Associates de la serie. Padilla, además afirma que cada capítulo de la serie, por su perfección en el tratamiento de resolución de crisis, "podría ser ejemplo didáctico 
de información y comunicación en las aulas universitarias (...) Sin embargo, el análisis de los episodios puede quedar abierto a muchas otras teorías, igualmente interesantes" (2014: 142).

Rodríguez Vidales explica que "series como El ala oeste de la Casa Blanca, House of Cards o Borgen también muestran a la perfección la estrategias y técnicas comunicativas propuestas en el modelo de Ray Eldon Hiebert (1981: 3-13) ${ }^{4}$. Vemos cómo los políticos son capaces de convivir y utilizar a los periodistas, a los que necesitan para que su mensaje llegue al electorado. Y cómo éstos, los periodistas, conscientes de su poder, saben emplear sus cartas, logrando así sus grandes exclusivas, filtraciones, o provocar la dimisión de algún que otro presidente, ministro u otro cargo político" (2015: 795), estrategias que en Scandal están casi desaparecidas por representar un periodismo poco o nada investigador.

\section{Conclusiones}

La calidad de la ficción televisiva norteamericana atraviesa uno de sus mejores momentos, e incluso una nueva edad dorada, y así se refleja en el éxito que tiene dentro y fuera de sus fronteras, como sucede con los espectadores españoles (Cascajosa Virino, 2007). A pesar de que estas series se desarrollan en ámbitos muy dispares, las centradas en el ámbito político ofrecen una estrecha relación entre el poder -normalmente en la esfera de la Casa Blanca-, y la comunicación, que es totalmente interesada pero, a la vez, cuidadosamente maquillada de cara a la población. Así, los gabinetes de prensa del entorno presidencial, las campañas realizadas con objetivos electorales o, en definitiva, los entramados que se tejen para aupar o destruir a los candidatos políticos muestran, representan y reconstruyen el vínculo entre la política y la comunicación en el escenario más poderoso de Estados Unidos, como se constata en las series estudiadas. Asimismo, el poder de la televisión como medio de comunicación de masas tiene una influencia decisiva en la sociedad, especialmente en un momento en el que se consumen más productos de ficción televisivos que cinematográficos por su elevada calidad. En este sentido, los conceptos de democracia líquida y pensamiento líquido, propios de una

\footnotetext{
${ }^{4}$ Refiriéndose al poder blando, el que los políticos ejercen sobre la población de forma indirecta, ayudados por los medios, y no a base de legislación y medidas "oficiales" democráticamente entendidas, entendido como poder duro.
} 
sociedad en continuo cambio como la actual, adquieren un especial protagonismo al estar presentes en series que reúnen a millones de espectadores en todo el mundo y que ponen en tela de juicio la relación entre el poder y los medios.

En House of Cards la manipulación de la comunicación desde la Casa Blanca es la tónica habitual. Además, pone de manifiesto que el presidente no es quien tiene la última palabra en este ámbito, sino que son las personas de su entorno más directo las que deciden de qué pueden habar los medios, qué es beneficioso o no para el partido en este caso el Partido Demócrata-, qué es lo que se puede denunciar, o qué temas son los que deben tratarse para desviar la atención de lo que realmente sucede. Así, los ciudadanos, que suelen ignorar este tipo de situaciones, son los últimos en conocer la verdad, pero los medios se prestan a este juego porque necesitan el apoyo del poder para mantenerse. Por ello, no se puede decir que se trata de una clara manipulación del poder a los medios, sino de una relación de total conveniencia que refleja que ambos se necesitan. Lo curioso es que este interesado vínculo está dominado por los abusos, las drogas, el sexo, la extorsión y el asesinato, y, además, los espectadores siguen la serie de forma fiel en distintos países en lugar de escandalizarse. Esto la sitúa en el lugar opuesto a El ala oeste de la Casa Blanca, donde se intentaba mantener un idealismo democrático tanto en la política como en los procedimientos de la propia comunicación, y se condenaban las calumnias y el arribismo (Sanmartín Pardo, 2007).

Tonny Soprano decía "No entiendo de ética, pero tengo normas", y parece que en la Casa Blanca de ficción, representada en Scandal, ni se entiende de ética ni se tienen normas. Se registra una democracia líquida, siempre al borde de la quiebra y siempre recuperada en su equilibrio inestable, gracias los métodos sucios y a la utilización de la prensa y los medios, que con la misma liquidez, miran hacia otro lado. En este caso, las relaciones de tipo sentimental y sexual entre los protagonistas adquieren una gran presencia y esto le otorga un carácter melodramático que la aproxima a la telenovela que tanto éxito proporcionó a la televisión norteamericana con títulos como Dallas (ABC, 1978-1991), Dinastía (ABC, 1981-1989) o Falcon Crest (CBS, 1981-1990). No obstante, resulta llamativo que sea una mujer negra la showrunner de la serie cuando 
son muy pocas las mujeres que desempeñan este rol en la ficción, y esto la vincula directamente con Judy Smith, en quien se inspira el personaje.

Ambas series son exitosas; abordan la compleja, complicada y enrevesada relación entre el poder político y los medios de comunicación; ponen de relieve que la manipulación sistemática, el sexo y los escándalos no son la excepción sino la regla; demuestran que la imagen está por encima de la integridad -aunque este valor se difunda a los americanos-; y revelan que ambos se necesitan para sobrevivir en una sociedad líquida que está en continuo cambio y que carece de compromiso y de principios. Esta tendencia televisiva tiene asegurada su continuidad con Scandal y House of Cards y también con la inminente The Resident (Fox 21), de nuevo centrada en la Casa Blanca.

\section{Bibliografía}

Bauman, Z. (2006): Vida líquida, Barcelona, Paidós.

Cascajosa Virino, C. Ed.) (2007): La caja lista. Televisión norteamericana de culto, Barcelona: Laertes.

Crisóstomo, R. (2015). "Política, su señoría: espacios políticos en The Good Wife", en Anna Tous (ed.): La política en las series de televisión. Entre el cinismo y la utopía, Barcelona: UOC, pp. 37-56.

Chuck, T. (2011): "Representing the Presidency. Viral Videos, Intertextuallity and Political Partcipation", en Michael Kackman and allii.: Flow TV. Television in the Age of Media Convergence, New York: Routledge.

De Bono, E. (2006): El pensamiento lateral, Barcelona, Paidós.

Eilders, C. y Nitsch, C. (2015): "Politics in Fictional Entertaiment. An Empirical Classification of Movies and TV Series”, en International Journal of Communication, n 9 , pp. 1563-1587.

Everett, A. (2015): “Scandalicious. Scandal, Social Media and Shonda Rhimes' Auterist Juggernaut", en The Black scholar. Journal of Black Studies and Research, vol.45, Issue 1 .

García, M. (2014): "Mayoría de edad de las series televisivas americanas", en Crítica, $\mathrm{n}^{\circ}$ 904, pp. 104-107. En línea: $\underline{\text { http://www.revista- }}$ critica.com/administrator/components/com_avzrevistas/pdfs/e3fa601512ecd4a9eff6f6aa 
9234d518-994---Las-migraciones-en-un-mundo-globalizado.pdf $\quad$ (Consultado

el 18/03/17).

Hughes, D. (2011): Pensamiento líquido. Cambiar la perspectiva para conseguir el éxito, Barcelona: Empresa activa.

Padilla, G. (2014): "El estudio del Análisis Transaccional aplicado a la Comunicación de crisis en la serie Scandal", en Revista de Análisis Transaccional y Psicología Humanista, $\mathrm{n}^{\mathrm{o}} 71$, pp. 287-304.

Padilla, G. (2014): “Teoría de la información y de la comunicación en una serie de televisión: Scandal", en Historia y Comunicación social, vol.19, n especial, febrero, pp.133-144.

Rodríguez Vidales, Y. (2015): "Política y poder en las series de televisión", en Opción, vol.31, nº 4 , pp.775-796.

Ros, E. (2015): “Borgen: virtú neomaquiaveliana en los tiempos de la hybris política", en Anna Tous (ed.): La política en las series de televisión. Entre el cinismo y la utopía, Barcelona: UOC, pp. 157-188.

Sanmartín Pardo, J. (2007): "El idealismo democrático en El ala oeste de la Casa Blanca", en Cascajosa Virino, C. (Ed.): La caja lista. Televisión norteamericana de culto, Barcelona: Laertes, pp. 269- 287.

Tous, A. (2015): “The Newsroom y la política. ¿Una carta de amor al periodismo?, en Anna Tous (ed.): La política en las series de televisión. Entre el cinismo y la utopía, Barcelona: UOC, pp. 101-124.

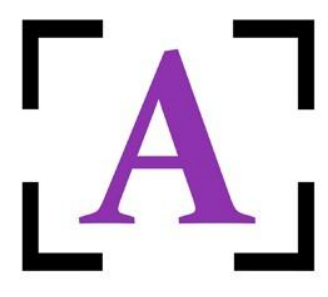

\section{Grupo de Investigación} AdMIRA

Análisis de Medios, Imágenes y Relatos Audiovisuales 